\title{
Exploring teacher-student interactions: communities of practice, ecological learning systems - or something else?
}

Abstract

A small-scale action research project was used to consider the policy and rhetoric surrounding development of the 'expert learner' and how this might be further explored to provide opportunities for learners to have greater direct involvement in reflection and discussion with teachers. The research was based within a Further Education setting, using participants from an 'HE in FE' curriculum area: teacher education. It sought to explore how involving students as partners in the peer observation process might be used to engage with student voice and enhance the teaching and learning experience for all involved.

To evaluate the creation, sharing and development of teaching and learning which might be generated in such circumstances, the research used two theoretical frameworks to analyse the data: communities of practice and ecological learning systems. This paper reviews the literature around these two frameworks and critically reflects on the influences of these approaches in communities of teaching and learning. Analysis of interviews, and the interactions and dialogue contained within these, revealed something else happening within these connections. As such, it considers the opportunities facilitated in this context and how development of a newly-devised continuum of practice may be used to enable professional dialogue to enhance student-teacher interactions.

Key words: communities of practice; ecological learning systems; communities of learning; student voice; professional dialogue; observations. 


\section{Introduction}

At the macro layer, much policy has emerged over the past decade in relation to learner voice and the need to find a way to 'engage' with our students (DfES 2003, 2005, 2006a, 2006b; LSC 2007; Framework for Excellence 2007; QIA 2008). This has generated a number of responses: the use of feedback surveys to seek out the voice of individuals (micro layer); the 'collective' representations collated via student bodies (meso layer); or at the level of 'organisational' development, the integration of students as member of governing bodies (exo layer). Whilst there is scope for these layers to be connected, frequently this is quite linear - almost one-directional - contributing to external and internal quality assurance measures based around teaching and learning. As such, there are missed opportunities to utilise potential areas of interaction in a more fluid, bi-directional format; those points whether emerging from 'process', or created by individuals - which exist within and across these layers.

\section{Research aims}

The focus of this research was to explore how we engage with the 'student' voice and to consider why we seek out that voice at all. Looking beyond quality assurance measures, of the 'you said/we did' feedback scenarios the impetus was on searching for something deeper. The aim was to understand and identify what the benefits could be for students, for teachers, for organisations and for policy - the four system layers. It took an area where there was sparsity of research in the post-compulsory 
education sector (Collinson 2007; Forrest et al. 2007; Mitra 2008; Bahou 2011) and considered how 'student voice' might be used to improve the teaching and learning experience for all those involved. For the student, this was about benefit to them in terms of improving their ability to engage with learning at a deeper level - to become, or improve their capacity to be, expert learners (QIA 2008). For teachers, the aim was to seek out ways in which they could engage with their students in a 'different' type of conversation. From an organisational perspective, it was about reviewing how peer observations might take place in a way that would incorporate the student voice in a more dynamic context. In terms of the wider macro layer, there were considerations for teacher practice and teacher development.

\section{Research design}

Wanting to make an impact at practitioner and learner level, the study was designed with an action research interpretivist epistemology (Bryman 2008), using the platform of peer observations. Interested in finding out what individuals thought was happening, the ontological perspective was a phenomenological one (Stringer 2004; Hall 2014). Working with a small team of teacher training staff and their students this original study was conducted as "research with, rather than on practitioners" (Reason and Bradbury 2006, xxv). There were eight participants in this 'HE delivered in FE' curriculum area who volunteered to contribute to the research over a twelve month period, and to be available for initial and follow-up interviews (Kvale and Brinkmann 
2009) throughout that time: participants comprised of teaching staff, second year students and a curriculum manager. To gain a depth of understanding in relation to the phenomenological perspectives (Stringer 2004; Hall 2014) participants were interviewed using a semi-structured format (Kvale and Brinkmann 2009); post-observation discussions took place between teacher and student: all conversations were recorded and transcribed for thematic coding and qualitative analysis (Mason 2002).

Participant contributions varied: from individual perceptions about the process - motivation for involvement, hopes and expectations, and 'looking back'; to the actual observations and the dialogue within these 'partnerships'; the reflections from those who were 'observed'; and finally to the broader overview provided by the curriculum manager. As the curriculum area delivered teacher training, the 'student' participants were trainee teachers, so in this respect the 'sending' and 'receiving' contexts (Lincoln and Guba 1985) could reasonably be expected to be similar for all participants - teaching.

Within the research, however, there was a different relationship at play, and mindful of the potential for ethical, or power, issues (Cockburn 2005) which might arise from sending students in as partners with teachers from the course they were enrolled on, it was also important to ensure that this was addressed through detailed consideration of the research design and the process for obtaining informed consent (Sin 
2005). Having established that all participants had similar curriculum context knowledge around teaching and learning, this did mitigate the potential for participants to be prevented from being able to be involved in any potential 'observation' discussion topics.

The course in question, founded in teacher education, was delivered over a two year period so this provided scope for second year students to complete their observations in a first year setting. In this way, student participants would not be observing sessions in which their student peers were present, nor contributing to observation feedback on their current second year tutors. This did mean, however, that students were partnered with teaching staff from their year group and this was taken into account throughout the research. For these volunteer participants this did remove some of the anxiety which might have been present had the research partnered these students with unknown teaching staff. However, this is an aspect which does need to be given methodological consideration.

The primary intention of the research was to identify ways to improve student-teacher dialogue and thus to improve the teaching and learning experience for all (LSC 2007; QIA 2008; Cain 2011). The peer observation process was used to facilitate this dialogue as it provided a familiar teaching and learning platform within which a professional dialogue could be developed. It also provided opportunities to explore 
what might happen as a result of pairing students with teachers within this context (Hall 2012). However, what came out of these conversations, was clear evidence that for the 'students', their identities (Turner et al. 1994; Turner 1999) and sense of self-concept (Cooley 1902; Oyserman et al. 2011; Schaffer 2000) were constructed in relation to 'affective perceptions as well as competency perceptions' (Hughes et al. 2011, 278). They had student-teacher expectations and defined relationships with their lecturing staff - they were interested in exploring ways to be both more effective students, as well as more informed teachers. Within their 'student' context, therefore, the sending/receiving identities (Lincoln and Guba 1985) were different from their identities as teachers.

Basing such conversations around a shared observation provided opportunities to reinforce the learning experience for all parties: development of metacognitive skills (Celuch et al. 2010; Veenman et al. 2006) and reflexivity for the students; a sense of ownership of their own learning; expanding their knowledge through involvement in the process and subsequent discussions (DeFur and Korinek 2010); and providing a sounding board, or 'reflective' challenge to the teacher's perceptions.

Seeking ways to positively contribute to the development of learning in a 'professional' environment this research had the intention of broadening the scope of those involved. Rather than having only teachers 
collaborating (Harris and Jones 2010), even if the focus was on actively seeking to change their practice, this would not have included the students' voice: and this is what contributes the essence of this paper. Therefore, the research was structured to ensure that any learning partnership, or community, engaged with both teachers and students. As such, it was designed so that the paired student and teacher participants would observe a taught class, and make notes on a pro-forma which was designed to act as a scaffold for their observation comments and for the subsequent post-observation discussion. The pro-forma provided a number of 'prompt' questions, such as: what opportunities for learning do you feel happened in the session; what made you think this; what was happening at the time; what contributed to this; were there any times when you felt that learning was not taking place? The 'observing pair' engaged in a sharing of views and understanding arising from the observation and from within their subsequent post-observation discussion: feedback was then passed back via the teacher, to the colleague who had been observed. This limited any ethical or potential power issues (Cain 2011) which might have arisen had the student participant been directly involved in this face-to-face feedback.

This paper focuses on the interactions and interviews with the two observing pairs, referring to them as Teacher 1/Student 1 and Teacher 2/Student 2: selected quotes are provided from recorded interviews and discussions which focused on the actual observation. 


\section{Literature review}

As the aim was to explore these 'communities', the language used in the exchanges, the nature of the relationships and the potential to enhance learning for both teachers and students, two theoretical frameworks were identified as appropriate to support the research. These included communities of practice (Lave and Wenger 1991; Wenger 1998, 2000; Amin and Roberts 2008; Mitra 2008) and as the literature review progressed, ecological learning systems (Bronfenbrenner 1979; Boylan 2005; Hodgson and Spours 2009). When comparing these frameworks, a community of practice initially felt more recognisable- a familiar context of 'master - apprentice' where norms and behaviours become established, with language and knowledge acquired as relevant to the subject or professional discipline. As these conversations and reflections were contained within a 'teaching' context, initial explorations of the data were focused on analysis of the findings around a recognised - and recognisable - community of practice (Lave and Wenger 1991): 'master' teachers developing the skills and expertise of the 'apprentice' student teachers through dialogue and the 'offering up', or passing on, of practice. This potentially hierarchical teacher-student relationship, however, could be constrained by limited opportunities for bi-directional feedback or development. Similarly, it was important to recognise issues which might arise around the very action of 'enabling' students to access such situations, as teachers 'let go' and allow learners: 
monitored and measured by tutors who are in a position to both allow and

disallow students from exercising such responsibility. (Marsh et al. 2001, 385)

Looking further into the literature, an additional model emerged: an ELS - an ecological learning system (Bronfenbrenner 1979; Boylan 2005; Hodgson and Spours 2009). Whilst still focusing on interactions within and across system layers, the 'development' opportunities had potential to be viewed as more collaborative, with a greater degree of 'inter-action'. Rather than the structured creation of norms and behaviours, the acquisition of 'language and stories', which might indicate an acknowledged position within a defined community of practice, an ELS is much more fluid with an emphasis on interplay and collaborative connectivity.

This paper therefore now considers the literature around these two frameworks and in doing so, it reflects on a new model - a continuum of practice - which emerged from the research (Hall 2012) and which is suggested as a means of bridging, and interconnecting, the system layers (micro and meso) involved in the facilitation of opportunities for meaningful professional dialogue between students and teachers.

\section{Communities of practice}

Traditionally associated with vocational contexts, communities of practice provide a lens through which to evaluate situations whereby someone with less knowledge of a subject acquires greater knowledge and awareness through their interactions with a more experienced other - 
usually through direct involvement in appropriate activities (Lave and Wenger 1991). If a community of practice is thought of as a circle, and any interactions as being contained within that circle, then the placement of the interaction can be anywhere from the edge (identified as legitimate peripheral participation) for a 'novice' to locations moving closer to the centre as one's expertise grows: the point of 'mastery' (Lave and Wenger 1991). These stages of 'belonging' are represented by Wenger (2000, 2010) as varying degrees of 'mutuality': engagement, imagination and alignment. These aspects - whether enacted as separate components or in combination - provide a means through which individuals can engage with 'co-construction' of beliefs and decision-making processes. This, in turn, enables increasing access to that community and an expectation of commitment to defined and accepted roles within that community; thus strengthening bonds and fostering mutual respect, trust and norms (Rudduck and Fielding 2006).

However, even within an overarching 'community' of teachers, there will be sub-communities of practice representing not only varying levels of expertise, but also different skills sets and working contexts: compulsory and post-compulsory sectors, further education, higher education (HE), adult education, and vocational, etc. The skills, and the associated behaviours and norms that support particular knowledge acquisition, may be considered as being contained within these separate 'sets'. Teachers who inhabit a community of practice could, therefore, be modelling this master-apprentice approach with their students - and with 
each other - within a very specific knowledge acquisition setting, established practices and social processes being used to create accepted 'ways of being or identities' (Tusting 2005). Such 'learning partnerships' (Wenger 2010) recognise the potential for co-learning, building on the familiar domains of communities of practice: mutuality, engagement, norms and behaviours, shared repertoires, etc. They indicate a 'trust' that may arise from acknowledgement that the other participant(s):

“...come from a place of experience and [will] therefore make contributions that are very likely to be relevant to practice. It is trust in the learning capability of a partnership." (Wenger 2010, 194)

There are issues within this, however, in relation to the 'discipline' of the community and who should be included; the dynamics of the community; the boundaries; and what these 'landscapes of practice' might look like (Wenger 2010). This raises questions around whether the focus is on how to 'bridge' two separate communities, or how to integrate - or subsume - one into the other. If students are perceived as the 'apprentices' through their involvement in the observation process, could they be considered as being absorbed into the 'culture of practice' (Lave and Wenger 1991) as a result? Would their deeper engagement with the teaching community, be viewed as a step towards the centre?

As language is a key element, and considered as evidence, of 'belonging' within a community of practice - knowing 'how' to talk becomes as important as the content of what is spoken:

For newcomers then the purpose is not to learn from talk as a substitute for legitimate peripheral participation; it is to learn to talk as a key to legitimate 
peripheral participation. (Lave and Wenger 1991, 127)

Students may therefore choose to align their opinions with the teacher, and so contributions to the discussion about the observation could merely evolve into tacit agreement within the observation partnership (Wenger 2000) and this is explored at a later point in this paper.

Other key elements which communities of practice (Wenger 1998, 2010) bring into question are issues around power and hierarchy, so a student may not only struggle to find the appropriate language with which to make their thoughts explicit, they may also have concerns about how their 'contributions' are perceived by the teaching staff involved. If a student, or teacher, is seeking to strengthen that bond within the community of practice, and to adopt the role with which they are associated, they may act in such a way as to reinforce that individual role identity in order to develop this respect, trust and norms (Ruddock and Fielding 2006). As such, this may introduce aspects of conflict and tensions within the teacher-student interactions which could act as barriers to a genuine exchange of opinions as individuals endeavour to 'fit' their perceived persona.

If identities can be defined, or contained, in this way, this might indicate that there is limited, or no, potential to change them within a community of practice. If the collective 'identity' of a community can be defined 'as much by whom and what they exclude as by what they contain' (Harris and Shelswell 2005, 168) it poses questions around what 
might be happening to enable, or hinder, access. Within these established community identities, we may see members of a community become boundary 'spanners' (crossing one specific boundary over time - perhaps working regularly with another team); or boundary 'roamers' (the networkers who move knowledge around and create connections), Wenger (2000). They may 'broker' knowledge as a result of a personal relationship or act as a boundary 'outpost' to explore new territory and bring back information. Yet they will do so within the bounds of their community and the expectations and defined parameters of their community identity.

The research looked for what opportunities might exist to develop these inter-actions so that they move beyond and across any traditional, and potentially hierarchical, boundaries and in doing so become more collaborative and fluid - more agentic in their origins and outlook.

\section{Ecological learning systems}

With regards to ecological learning systems (ELS) there is greater emphasis on the ways in which individuals interact and develop: there may be an overarching ecological structure (similar to the overarching community of practice), however within this environment 'each level exerts reciprocal influences on the others' (Hodgson and Spours 2009, 10). Within an ecological learning system each of the system levels (micro and meso) can be thought of as discrete entities: there will be 
interaction between the levels, but this will be bi-directional, even multidirectional if extending into the broader system levels (exo and macro). There is a collaborative aspect which seeks to engage 'different partners at different levels of the system as they prepare a shared framework for creative action' (Hodgson and Spours 2009, 17) and this may serve to develop that same sense of shared purpose and values - the norms - that are present within a community of practice. Where the difference becomes apparent is around the concept of 'partnership': these norms are co-created within an ELS, indicating a shared development of any outcomes (Fuller et al. 2005; Collinson 2007; Forrest et al. 2007; Walker and Logan 2008).

Recent work undertaken by Hodgson and Spours (2013) has explored ecological models in relation to 14+ education and training, reviewing this in relation to "young people's identity and agency" (Hodgson and Spours 2013,216) and the role of education. Whilst not looking at the role of student voice, this study does concern itself with the perceptions students have of their education and potential to 'engage'. It considers eco-systems, using the "term 'ecology' in a neutral sense in that it describes a set of inter-dependent relationships" (Hodgson and Spours 2013, 216). The context is different, but there is a strong desire within both Hodgson and Spours (2013) and Hall (2012) to explore and examine what is happening within and between relationships - both for the students and for the 'professionals'. 
If interactions are not reliant upon an outcome which signals 'belonging' to a community of practice, then it is important to consider the motivations inherent in any 'co-working' situations. Individuals may be driven by a desire 'to realise their personal needs through participation in the satisfaction of collective needs' (Harris and Shelswell 2005, 173). However, this has potential for tensions to occur if individuals begin to identify with a number of different 'communities' with membership in one, creating marginalisation in another: a 'nexus of multi-membership' (Wenger 1998, 159). If the 'partnership' is viewed from an ELS perspective, then the links and bonds which are established as a result, are regarded as looser, with fluidity created around these communities. As a result, boundaries are more permeable, with a sense that 'agency' is achieved through a transactional relationship and engagement with one or more environments: it is not achieved as a result of belonging to a defined community of practice or having a defined identity as a result of that belonging.

The research was concerned with understanding what was happening within the interactions between teachers and students as a result of their partnership and collaboration in the peer observation process. Having initially undertaken a review of the data generated from the interviews and post-observation discussions, it became apparent that the two frameworks did not provide a means through which to interrogate the data effectively. There was something happening in the 
conversations which indicated the existence of a new and different model: a continuum of practice (Hall 2012) which could have the potential to bridge and work within and between these two existing frameworks.

\section{Continuum of practice}

Having explored the data and these two theoretical frameworks, key headings were identified and used to aid the thematic analysis of the data: these key headings formed the core of a new model. As the data analysis deepened, they were further developed to explore what these themes might look like, in terms of relationships; working together; information exchange; getting started/progress; knowledge; identity; language; reification; and power. There was no degree of importance attached to the ordering of the thematic headings however some themes were stronger in terms of the evidence and as such became more predominant.

\section{TABLE 1: A Continuum of Practice}

What emerged within the evidence was a picture of 'something else' being present when the coding and analysis was undertaken. The data did not represent either a master-apprentice model, or an ELS one. This new model - a continuum of practice - was required to enable a deeper understanding of the ways in which agency and interactions were demonstrated, and the oscillations evidenced in the conversations between a community of practice approach and/or an ecological learning 
system approach. There was a focus on the relationships and interconnectedness between the participants (micro and meso layers) and between the participants and their environment(s) - exo layer. What was not clear, was what specifically was driving the discussions. A desire to have one's identity ratified by a community; or a sense of independence, rather than inter-dependence, whereby collaborative exchanges and acknowledgement of relationships were evident, but not a reliance upon these to establish a sense of self. Within the conversations which took place during the research, there was evidence of both approaches: community of practice and ecological learning system. The former was evidenced in exchanges which expressed a sense of knowing one's place within the community, whether as a 'teacher' or as a 'student'. Teaching staff who were being paired with a student discussed their views as to what their perceptions were about what was motivating the student participants:

I'm sure they're both interested in going in to see any teacher because going in and observing teachers...it means you learn things about your own teaching by watching other people. [...] I'm sure that probably, one of the reasons they, they've volunteered must be that they want to engage with us in those conversations $[. .$.$] so it can be the process of observing, but possibly also the$ process of discussion is appealing as well. (Teacher 1, Hall 2012, 87)

When considering perceptions around being a second year student involved in this research, student participants felt there was knowledge to be explored from a personal perspective, but also to be disseminated to other students. Student 1 talked of being able to ' ... review my experience $[. .$.$] my impressions and also my knowledge from my first$ year. [... at being ...] Open to, to observe and see how the experience of 
the first year...how it is for them (first year students)' (Student 1, Hall

2012, 102). There was also deferment to the greater knowledge and expertise of the teacher whom they partnered in the peer observation, with references to, and acknowledgement of, being the 'pupil' and so to the presence of a teacher-student relationship (Cain, 2011).

When an ELS was evident, there was recognition from both the student and the teacher that they were both learners - each having knowledge which would be of value to the other: interactions displayed mutuality and fluidity and a capacity for identity and knowledge to be developed as a result of co-transactions. What was also evident from one of the teacher participants (Teacher 2) was that in order for this mutual interaction and agency to exist, they personally needed to adopt a 'facilitating' role initially in order to elicit as much information as possible from their student partner and so construct mutual interaction (Hall 2012). This also resulted in what was described as a 'liberating' experience. Having the opportunity for an initial 'objective' discussion with their 'fellow observer', before providing feedback to the member of staff observed, allowed this particular teacher to:

...come to the discussion [with the observed teacher] with a clear idea of the key development points. I felt that this enabled me to facilitate the discussion towards stronger critical viewpoints than I have done during previous peer observations.... [allowing] me to get all of the minor points 'off my chest' as well as the ability to check, clarify and confirm issues [with student partner] (Teacher 2, Hall 2012, 143)

This participant also acknowledged, however, that they needed to maintain their self-awareness during the teacher-student dialogue to prevent a veering towards 'a traditional didactic teaching role', which 
could have been indicative of the inherent 'teacher-student position' (Hall 2012, 142). This 'position' could also have the potential to encourage a student to deliberately align opinions - whether to seek approval, or to attempt to demonstrate a stronger identity within the community through affirmation of the other's dialogue: the response of the teacher to this is crucial.

So, how are such statements explored? Does it become a deeper dialogue - an exploration and co-construction of new knowledge, or does it become an opportunity for the more experienced 'other' to challenge the statement? If the latter, when statements are made by the student which cannot then be clarified or expanded upon when tested, within the bounds of a community of practice the limitations of the student's knowledge could be exposed and lead to frustration, discomfort and potential power imbalances. During one post-observation discussion, Student 1 had talked about the need to provide learners with the 'systems, the processes, the formulae, to problematize learning'. Within the discussion, this was questioned quite strongly by their partner, Teacher 1 , who was seeking examples which could be further explored: the student was unable to provide specifics, only able to refer to this 'in general'. The student was asked to clarify this four times within the conversation: was this therefore an hierarchical imbalance, master challenging apprentice - a community of practice approach with the apprentice realising that they did not have the knowledge to 'back up' their statement? Or simply frustration on the part of Teacher 1 in trying to get 
Student 1 to elaborate, and not being successful.

From an ELS standpoint, which was more prevalent in the second paired discussion, there was value in discussion of differing viewpoints, of recognition of an individual's knowledge - of a sense of 'self' (Cooley 1902; Oyserman et al. 2011). Individual views were provided by both student and teacher, with exploration around the point in question:

I agree with you, well, I agree with certainly the issue of variety ... $[\ldots] \ldots$ One thing I'm not sure I really agree with you on is 'everybody contributing'... (Teacher 2, Hall 2012, 94)

....but yeah, come back to that...[...] . I started.... I did a little contributions grid [exploration of this continued within the discussion]... (Student 2, Hall 2012, 94)

There was no sense of a need for justification; time was allowed for an exploration of the issue, of consideration of both viewpoints, and of mutual influence. This was more representative of an ELS approach.

Repeated listening to the post-observation conversations revealed a sense of something else going on. As might be expected, there were 'interjections' within and across the dialogue - but this was not only the usual conversational to-and-fro which might be expected (Hall 2012). To evaluate whether this had any contribution to make towards the analysis of the data, and to greater knowledge in relation to the two frameworks, an additional analysis was done around these interjections. Did they display basic 'concurrence' of opinion (short responses such as 'yes', 'no'); stronger 'reinforcement' from the second speaker (greater affirmation, longer or stronger, comments); or 'disagreement/query'? A 
note was also made in relation to 'joint laughter' which might be indicative of 'insider knowledge' as in communities of practice. The data is displayed in the following table.

\section{TABLE 2: Analysis of Post-Observation Discussions}

What this revealed was little difference in terms of the interjections made by either of the teachers whilst their student partners were speaking. However, there was a substantial difference between the interjections made by the students when their teacher partners were speaking. Student 2 had more than double the interjections of Student 1 (85 to 38), with 69 instances of concurrence compared with 4 from Student 1: these were comments which exhibited verbalisation of 'head nodding'. There was a 'consensus of agreement' - but this came from a feeling that there was an equality of status and sense of freedom within the conversation (Hall 2012). Teacher 1/Student 1 felt more 'restrained' at this level. However, under reinforcement the position changed with Student 1 displaying 33 instances, against 16 for Student 2: these were examples of strong agreement with the Teacher's comments, and sometimes including longer examples, or additional comments to reinforce those presented by the Teacher. Student 1's interjections were still quite short, but represented 'affirmation' of Teacher 1's dialogue; Student 2's interjections were longer, with some affirmation, but also contribution of 'original thoughts' (Hall 2012). There was little in terms of disagreement/query or joint laughter to be explored in greater detail. 
Where there was a sense of an ELS approach, there was greater 'ebb and flow' within the conversation, of frequent 'transactions' and exchanges of dialogue. This was not just about 'knowing what others know' (Lave and Wenger 1991; Wenger 2010) but of acquiring and disseminating knowledge through 'inter-action': active decision-making and agency, rather than straightforward assimilation of knowledge. The conversations in both approaches were quick to get underway, as might be expected as all participants have a familiarity with the context, and each other, however the language in the conversation between the pairings was different. In the first pairing (Teacher 1/Student 1) the language was more formal, linked closely to jargon and 'conformance' to the expectations of teaching and learning - to a community of practice. Within the ELS, although purposeful, there was an informality within the exchanges between participants - this was a 'shared story' but co-created, and with an easy production of joint knowledge (Hall 2012).

\section{Discussion}

Reviewing the research and the evidence, a number of implications were drawn out in relation to individual student and teacher learning (micro layer); to teaching practice (meso and macro); and to the ways in which organisations engage with their 'student voice' (exo). These will be explored shortly, but at this stage it is worth reminding ourselves of the initial drivers for this research: an exploration of policy and practice (DfES 2003, 2005, 2006a, 2006b; LSC 2007; Framework for Excellence 2007; QIA 2008). During the last decade there has been a 
desire to engage in a better way with our students - our learners.

Preliminary considerations of these drivers might question whether a community of practice approach could be linked to such an agenda so rooted in 'personalisation' (LSC 2007; QIA 2008) as such communities are traditionally embedded in the master-apprentice model. Perhaps then, it would not be unreasonable to assume that there is greater potential for the collaborative, agentic environment of an ecological learning system to align more easily with this political agenda.

\section{Frameworks}

The two frameworks have similarities: working within and across structures and layers - the micro, meso, exo and macro. It is the ways in which these work which is different, and as a result therefore, the ways in which they can be worked with, will be different and will provide potential to adopt the continuum of practice alongside.

If taking a communities of practice stance then it would not be unreasonable to assume that such a relationship could be problematic and that there may be a reluctance to be perceived as an 'apprentice' or novice, rather than a fellow teacher. An ecological learning system approach may enable a less hierarchical context and open up a two-way dialogue more readily as all parties recognise the value of each other's contributions within the relationship; and importantly, what each can gain from the other. 


\section{Partnerships}

The teaching staff involved in the study recognised their role in 'modelling' (Hall 2012) good practice through their approach to the peer observation, but also through their engagement with the research and reflections on their own practice (Stringer 2004). Staff also acknowledged that through the involvement of students in this process, they could become more independent, rather than passive recipients of knowledge (Hall 2012):

\footnotetext{
....that understanding of the self and others is possible only when attempts are made to view experiences from 'the inside out'. But [in the process of recognising that] the inside is as challenging to learn about as the outside. (Marsh et al. 2001, 393)
}

However, it can also be seen that there are developmental requirements around the awareness, and expectations, of both staff and students (Cockburn 2005), and there are implications around power and relationships, language and knowledge, and how individuals establish, and perceive, their identities (Cain 2011). There is a responsibility which sits with the teacher to facilitate the process, to enable the learner in their participation and in doing so, provide them with a structured, supportive and above all 'safe' environment in which to explore their ideas around learning and to promote their metacognitive development (Schaffer 2000; Oysterman et al. 2011). There are accordingly points that need to be considered in relation to how we approach teacher education; how we engage with the student 'voice'; and how these strands can be brought together to further develop and support the peer observation process itself. 


\section{Peer observations}

Taking this aspect forward; the research established - and we also know - that whether 'qualified' or not, all of the participants can be categorised as 'members' of a professional community - teachers; yet perceptions of their positions within that community were different. The student participants also perceived themselves as members of a 'student' community and it was through engaging with the research that there was potential for these 'different' interactions with their 'teacher-educator' (Cockburn, 2005) to interfere with transparent and sincere dialogue. What became evident from the research is the indication that a 'developmental' approach to observations, in this case via a peer observation format, is a positive vehicle around which to create and develop a learning conversation. The partnership process involved in this approach was enabling for both teachers and students, facilitating opportunities for reflection, for the sharing and exploration of perceptions. The question is around how this was done, and whether discussions and implications for practice are best created through a community of practice or ecological learning system approach - or something else.

If interaction is bounded within a master-apprentice model, and reliance on a community to define one's identity, such conversations and dialogue are always going to have the potential to be contained - and constrained - within the boundaries, expectations, norms and behaviours of that community. If it happens as a result of collaborative exchanges, interdependent - but independent - relationships, then there is potential 
to move towards an ecological learning systems approach. It is for organisations to consider how they might integrate this approach into their strategies around teaching observations and student voice initiatives.

\section{Considerations}

In terms of limitations and generalizability, the research was small scale, although interviews and data analysis were reiterated throughout a 12 month period, so adding depth and richness to the findings. It sought to identify the ways in which actions and inter-actions occur, in relation to the different system layers (micro, meso, exo and macro). It focused on a teacher training curriculum area, so there are considerations around how it might 'travel' to a different curriculum area/student age range.

Using the data analysis from this research, the model which had the most productive outcome in terms of establishing collaborative dialogue, was a largely ecological learning system approach. Facilitating multi-directional working, with the capacity to shape and influence others, including self, being achieved not in a pre-defined sense of collective agency as with a community of practice, but through a sense of individual agentic behaviour embedded within the individual participants, and so with capacity to impact on self, on peers and on the organisation. What the continuum of practice provided, was a means through which to interrogate the data to arrive at fresh insights and understandings in relation to what was happening within the dialogue. The challenge for us as practitioners is to take these insights forward and to consider how they 
might transfer to other curriculum contexts or age groups. There is nothing within the data or findings to indicate that this should not be possible. However, even with experienced adult 'students', there was still the potential for teacher-student relationships and interactions to be influenced and it is crucial that any replications of this model take into account the importance of teaching staff acting as 'enablers' and 'facilitators' of this teacher-student dialogue (Hall, 2012).

\section{Conclusions}

The focus of this research was to explore opportunities for students and teachers to engage in productive, collaborative dialogue; to consider what it is about interacting with someone with more knowledge which might enable us to reflect on our own knowledge in greater depth. In doing this, however, it was not merely about having an impact on an 'individual', but on all parties involved in these conversations. It might be stated that a community of practice approach, whilst master-apprentice in nature, will still afford opportunities for both to develop their knowledge: one would still expect the 'master' to gain something from such conversations, but the received wisdom is that the emphasis will be on the 'apprentice'. So, what of the ecological learning system - how might this differ? With this there are no hierarchies, no accepted identities or preconceived relationships - this is about multi-directional opportunities for inter-action and co-construction: two frameworks - two ends of the continuum. 
What the emergent continuum of practice may provide for us is a way to examine how we might bridge, or oscillate, within and across these frameworks in order to open up new ways of engaging in discussions with our students; to inform our approaches to practice in order to 'liberate' our minds to the possibilities this may present. That we may be operating in different contexts really should not prevent us from attempting this within our own settings. After all, at the end of the day, we are still teachers and students, and we all have something to learn from each other if we can find the right way to listen. 


\section{References}

Amin, A. and Roberts, J. (2008) Knowing in action: Beyond communities of practice Research Policy Vol. 37, no.2: $353-369$

Bahou, L. (2011) Critical Review: Rethinking The Challenges and Possibilities of Student Voice and Agency. Educate - Special Issue. January 2011 pp 2 - 14

Available from: http://www.educatejournal.org/

Boylan, M. (2005) School classrooms: Communities of practice or ecologies of practices? Paper presented at $1^{\text {st }}$ Socio-Cultural Theory in Educational Research, September 2005 Manchester University, UK.

Available from: http://orgs.man.ac.uk/projects/include/experiment/mark_boyland.pdf Bronfenbrenner, U. (1979) The ecology of human development: Experiments by nature and design. Cambridge, MA: Harvard University Press

Bryman, A, (2008) Social Research Methods, $3^{\text {rd }}$ edition, Oxford University Press: New York. Cain, T. (2011) Teachers' classroom-based action research. International Journal of Research and Method in Education Vol. 34, no. 1: 3-16

Celuch, K., Kozlenkova, I., and Black, G. (2010) An exploration of self-efficacy as a mediator of skill beliefs and student self-identity as a critical thinker. Marketing Education Review. Vol. 20, no. 3: $255-264$

Cockburn, J. (2005) Perspectives and Politics of Classroom Observation. The Research and Development Bulletin Vol. 3, no. 2: 45 - 55

Collinson, D. (2007) Leadership and the Learner Voice in Researching Leadership in the Learning and Skills Sector: By the Sector, On the Sector, For the Sector Vol. 4: 4 - 29 Cooley, C. H. (1902) Human Nature and Social Order. Charles Scribner: New York DfES (2003) $21^{\text {st }}$ Century Skills: Realising our potential CM 5810, Norwich: HMSO Available from: www.dfes.gov.uk/skillsstrategy/_pdfs/whitePaper_PDFID4.pdf DfES (2005) $14-19$ Education and Skills, CM 6476, Norwich: HMSO Available from: www.dfes.gov.uk/publications/14-19educationandskills/ DfES (2006a) FE White Paper Further Education: Raising skills, improving life chances Available from: www.dfes.gov.uk/publications/furthereducation ) DfES (2006b) Personalising Further Education: Developing a vision Available from: www.dfes.gov.uk/consultations/downloadableDocs/DfES\%20Personalisation.pdf DeFur, S. H. and Korinek, L. (2010) Listening to Student Voices. The Clearing House: A Journal of Educational Strategies, Issues and Ideas. Vol. 83, no. 1: 15 - 19

Forrest, C., Lawton, J., Adams, A., Louth, T., and Swain, I. (2007) The Impact of Learner Voice on Quality Improvement in Leadership and the Learner Voice in Researching Leadership in the Learning and Skills Sector: By the Sector, On the Sector, For the Sector Vol. 4: 4-29 Framework for Excellence (2007): Raising Standards and Informing Choice Available from: http://ffe.lsc.gov.uk )

Fuller, A., Hodkinson, H., Hodkinson, P. and Unwin, L. (2005) Learning as peripheral participation in communities of practice: a reassessment of key concepts in workplace learning. British Educational Research Journal, Vol. 31, Issue 1: 49 - 68

Hall, V. J. (2012) "Observations: a vehicle for enabling learner voice and developing expert learners" (Centre for Professional Development, Staffordshire University. Unpublished Ed.D. thesis).

Hall, V. (2014). Peer Observations as a Vehicle for Engaging with the Student Voice: A Phenomenological Inquiry. In SAGE Research Methods Cases. London, United Kingdom: Sage Publications, Ltd.

Harris, S., R., and Shelswell, N. (2005) Moving Beyond Communities of Practice (pp158 - 179) in Beyond Communities of Practice. Language, Power and Social Context (eds) Barton, D. and Tusting, K. New York: Cambridge University Press.

Hodgson, A. and Spours, K. (2009) Institution for Lifelong Learning: Collaborative Local Learning Ecologies: Reflections on the Governance of Lifelong Learning in England. Sector Paper 6.

Kvale, S. and Brinkmann, S. (2009) Interviews. Learning the Craft of qualitative Research Interviewing. California: Sage Publications Ltd. 
Lave, J. and Wenger, E. (1991) Legitimate peripheral participation in communities of practice, pp 111 - 126, in Supporting lifelong learning, Vol. 1, Perspectives on learning (eds) Harrison, R., Reeve, F., Hanson, A. and Clarke, J. (2002) London: Routledge Falmer.

Lincoln, Y. S., and Guba, E. G. (1985). Naturalistic inquiry. Beverly Hills: Sage Publications. LSC (2007) Developing a Learner Involvement Strategy: A handbook for the Further Education sector http://www.excellencegateway.org.uk/page.aspx?o=207689

Marsh, C., Richards, K., and Smith, P. (2001) Autonomous learners and the learning society: systematic perspectives on the practice of teaching in Higher Education. Educational Philosophy and Theory. Vol. 33, nos. 3 and 4:381 - 395

Mason, J. (2002) Qualitative Researching (Second Edition). London: Sage Publications. Mitra, D. L. (2008) Balancing power in communities of practice: An examination of increasing student voice through school-based youth-adult partnerships. Journal of Educational Change, Springer Science and Business Media B.V. pp $221-242$

Oyserman, D., Elmore, K., and Smith, G. (2011) Self, Self-concept and Identity in Handbook of Self and Identity (eds) Leary, M., and Tangney, J. (2011) New York: Guildford Press.

Quality Improvement Agency (2008) Exploring the concept of the expert learner Available from: http://tlp.excellencegateway.org.uk/tlp/xcurricula/developing-the-expertlearner.html

Reason, P. and Bradbury, H. (2006) Handbook of Action Research. London: Sage Publications. Rudduck, J. and Fielding, M. (2006) Student voice and the perils of popularity. Educational Review. Vol. 58, no. 2: $219-231$

Schaffer, H. R. (2000) Social Development. Oxford: Blackwell Publishers.

Sin, C. H. (2005) Seeking Informed Consent: Reflections on Research Practice

Available from:

http://soc.sagepub.com/cgi/content/abstract/39/2/277

Stringer, E. (2004) Action Research in Education. Ohio: Pearson Merrill Prentice Hall

Turner, J. C. (1999) Some Current Issues in Research on Social Identity and Self-categorisation Theories pp 6 - 34 in Ellemers, N., Spears, R., and Doojse, B. (eds) Social Identity: context, commitment, content. Oxford: Blackwell.

Turner, J. C., Oakes, P. J., Haslam, S. A., McGarty, C. (1994) Self and Collective: cognition and social Context. Journal of Personality and Social Psychology. Vol. 20, no. 5: 454-463 Walker, L., and Logan, A. (2008) Learner Engagement. A review of learner voice initiatives across the UK's education sectors. Available from: www.futurelab.org.uk

Wenger, E. (1998) Communities of Practice. Learning, Meaning and Identity. New York: Cambridge University Press.

Wenger, E. (2000) Communities of practice and social learning systems, pp $160-179$, in Supporting lifelong learning, Vol. 2, Organising learning (eds) Reeve, F., Cartwright, M. and Edwards, R. (2002) London: Routledge Falmer.

Wenger, E. (2010) Communities of practice and social learning systems: the career of a concept. In Blackmore. C. (ed) Social learning Systems and Communities of Practice. Milton Keynes: Open University. 
TABLE 1: Continuum of Practice

\begin{tabular}{|c|c|c|}
\hline From $\ldots \ldots \ldots \ldots$ & \multirow[t]{2}{*}{ Continuum } & To......... \\
\hline \multirow[t]{2}{*}{ Communities of practice } & & Ecological learning systems \\
\hline & Relationships & \\
\hline \multirow[t]{2}{*}{$\begin{array}{l}\text { Sustained mutual relationships - } \\
\text { harmonious or conflicting }\end{array}$} & & $\begin{array}{l}\text { Transitory, more fluid - a functioning unit, } \\
\text { collaborative; changing temporal } \\
\text { orientations and relationships to other } \\
\text { structures }\end{array}$ \\
\hline & Working together & \\
\hline \multirow[t]{2}{*}{$\begin{array}{l}\text { Joint enterprise - shared ways of } \\
\text { engaging in doing things together }\end{array}$} & & $\begin{array}{l}\text { Interdependent relationships; impact on } \\
\text { other areas of work and life }\end{array}$ \\
\hline & Information exchange & \\
\hline \multirow[t]{2}{*}{$\begin{array}{l}\text { The rapid flow of information and } \\
\text { propagation of innovation }\end{array}$} & & $\begin{array}{l}\text { Bi-directional influences (transactional); } \\
\text { actor and environment affected by } \\
\text { engagement }\end{array}$ \\
\hline & $\begin{array}{c}\text { Getting } \\
\text { started/progress }\end{array}$ & \\
\hline $\begin{array}{l}\text { Absence of introductory preambles, as } \\
\text { if conversations and interactions were } \\
\text { merely the continuation of an on-going } \\
\text { process }\end{array}$ & & $\begin{array}{l}\text { New forms of collaboration, self-organising } \\
\text { and adaptive }\end{array}$ \\
\hline $\begin{array}{l}\text { Very quick set up of a problem to be } \\
\text { discussed }\end{array}$ & & $\begin{array}{l}\text { Routes and outcomes develop within } \\
\text { contexts that are changing and subject to re- } \\
\text { evaluation and reflection }\end{array}$ \\
\hline \multirow[t]{2}{*}{$\begin{array}{l}\text { Substantial overlap in participants' } \\
\text { descriptions of who belongs }\end{array}$} & & $\begin{array}{l}\text { Environment evolves and changes naturally } \\
\text { as a result of actions }\end{array}$ \\
\hline & Knowledge & \\
\hline \multirow[t]{2}{*}{$\begin{array}{l}\text { Knowing what others know, what they } \\
\text { can do and how they can contribute to } \\
\text { an enterprise; enactment of particular } \\
\text { roles (master-apprentice) }\end{array}$} & & $\begin{array}{l}\text { Strongest influences impact in two } \\
\text { directions: mutual interaction, including } \\
\text { peer-to-peer; active decision-making }\end{array}$ \\
\hline & Identity & \\
\hline $\begin{array}{l}\text { Mutually defining identities; value } \\
\text { placed upon knowledge and position } \\
\text { within the community; identity ratified } \\
\text { and given value by others }\end{array}$ & & $\begin{array}{l}\text { Capacity/influence to shape wider sense of } \\
\text { local identities; identity created through } \\
\text { transactions with others }\end{array}$ \\
\hline $\begin{array}{l}\text { The ability to assess the } \\
\text { appropriateness of actions and products }\end{array}$ & & Individual actors engage with context \\
\hline \multirow[t]{2}{*}{$\begin{array}{l}\text { Certain styles recognised as displaying } \\
\text { membership; 'collective' agency; } \\
\text { context engages with 'actors' }\end{array}$} & & $\begin{array}{l}\text { Sense of 'self' not as a component within } \\
\text { community of practice: agency }\end{array}$ \\
\hline & Language & \\
\hline $\begin{array}{l}\text { Specific tools, representations and } \\
\text { other artefacts }\end{array}$ & & Informal, not structured \\
\hline $\begin{array}{l}\text { Local lore, shared stories, inside jokes, } \\
\text { knowing laughter; conforming; } \\
\text { dependency }\end{array}$ & & Independent, non-conformist \\
\hline \multirow[t]{2}{*}{$\begin{array}{l}\text { Jargon and shortcuts to communication } \\
\text { as well as the ease of producing new } \\
\text { ones }\end{array}$} & & $\begin{array}{l}\text { Language represents the individual, the } \\
\text { system level, does not need to move across }\end{array}$ \\
\hline & Reification & \\
\hline \multirow[t]{2}{*}{$\begin{array}{l}\text { A shared discourse reflecting a certain } \\
\text { perspective on the world }\end{array}$} & & $\begin{array}{l}\text { Variable and changing orientations; } \\
\text { individual perspectives }\end{array}$ \\
\hline & Power & \\
\hline $\begin{array}{l}\text { Hierarchical, value placed upon } \\
\text { knowledge and position }\end{array}$ & & Devolution of power \\
\hline
\end{tabular}


TABLE 2: Analysis of Post-Observation Discussions

\begin{tabular}{|c|c|c|c|c|c|c|c|}
\hline 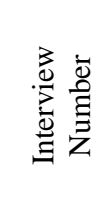 & 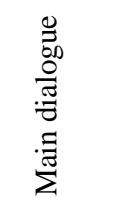 & 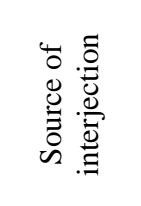 & 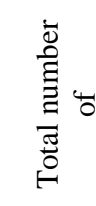 & 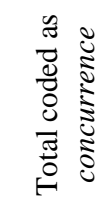 & 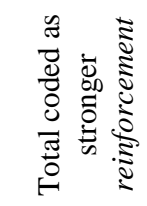 & 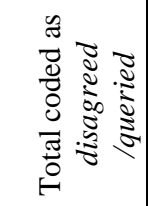 & 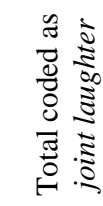 \\
\hline Five & Student 1 & Teacher 1 & 25 & 16 & 7 & 2 & 3 \\
\hline Six & Student 2 & Teacher 2 & 24 & 15 & 7 & 2 & 2 \\
\hline Five & Teacher 1 & Student 1 & 38 & 4 & 33 & 1 & 1 \\
\hline Six & Teacher 2 & Student 2 & 85 & 69 & 16 & 0 & 2 \\
\hline
\end{tabular}

